Article

\title{
Impact of Updated OECD/NEA Thermodynamic Database on the Safety Assessment of Radioactive Waste Repository Studied Using RESRAD-OFFSITE Code
}

\author{
Jun-Yeop Lee ${ }^{1, *}$, Sang June Park ${ }^{1,2}$ and Seokyoung Ahn ${ }^{1}$ (D) \\ 1 School of Mechanical Engineering, Pusan National University, 2, Busandaehak-ro 63beon-gil, Geumjeong-gu, \\ Busan 46241, Korea; xelidake2@pusan.ac.kr (S.J.P.); sahn@pusan.ac.kr (S.A.) \\ 2 Korea Hydro \& Nuclear Power (KHNP), 1655, Bulguk-ro, Munmudaewang-myeon, Gyeongju-si 38120, \\ Gyeongsangbuk-do, Korea \\ * Correspondence: jylee@pusan.ac.kr
}

Citation: Lee, J.-Y.; Park, S.J.; Ahn, S. Impact of Updated OECD/NEA

Thermodynamic Database on the Safety Assessment of Radioactive Waste Repository Studied Using RESRAD-OFFSITE Code. Appl. Sci. 2021, 11, 7269. https://doi.org/ 10.3390/app11167269

Academic Editor: Bruno Merk

Received: 14 July 2021

Accepted: 5 August 2021

Published: 6 August 2021

Publisher's Note: MDPI stays neutral with regard to jurisdictional claims in published maps and institutional affiliations.

Copyright: () 2021 by the authors. Licensee MDPI, Basel, Switzerland. This article is an open access article distributed under the terms and conditions of the Creative Commons Attribution (CC BY) license (https:// creativecommons.org/licenses/by/ $4.0 /)$.

\begin{abstract}
A RESRAD-OFFISTE computational code for the safety assessment model of a radioactive waste repository was utilized to evaluate the influence of the updated OECD/NEA thermodynamic database on the safety assessment model in terms of exposure dose. The solubility data as the input parameter for the RESRAD-OFFSITE code obtained with two different sets of chemical thermodynamic databases such as JAEA-TDB and amended JAEA-TDB reflecting the updates of the OECD/NEA thermodynamic database were calculated and compared with each other. As a result, almost identical exposure doses were obtained due to the remarkable similarity between the solubility data of various radionuclides for both chemical thermodynamic databases. In contrast, dramatic changes in exposure dose were observed with varying distribution coefficients. Thermodynamic calculations indicated that the aqueous species distribution can be significantly changed by the selection of a chemical thermodynamic database and thus the relevant distribution coefficient can also be influenced as a consequence. Accordingly, the result obtained in the present work indicated that (i) the impact of the updated chemical thermodynamic data was somewhat minor from the viewpoint of the solubility and (ii) the distribution coefficient, which can be sensitively influenced by the predominant chemical species, produced a remarkable change in the exposure dose. This work provided an insight into the precise exposure dose calculation in terms of the reliable estimation of the distribution coefficient by means of a surface complexation model, which can predict the distribution coefficient as a function of groundwater composition coupled with a chemical speciation calculation based on up to date chemical thermodynamic data.
\end{abstract}

Keywords: safety assessment; radioactive waste repository; chemical thermodynamic database; RESRAD-OFFSITE; PHREEQC

\section{Introduction}

For the reliable safety assessment of a radioactive waste repository, a systematic understanding of the migration behavior of radionuclides is essential, because a key criterion for an appropriate disposal strategy is the capability to isolate the harmful substances [1]. Various geochemical reactions such as aqueous complexation [2,3], solubility [4-6], sorption $[7,8]$, etc. can be quantitatively predicted by using relevant chemical thermodynamic data such as formation constant, solubility product constant, etc. Therefore, for the precise estimation of the chemical behavior of various radionuclides, it is of cardinal importance to employ the latest, updated, and comprehensively reviewed thermodynamic data for the relevant chemical thermodynamic calculation.

Since 1992, OECD/NEA has been establishing a reliable thermochemical database $[9,10]$, also called as OECD/NEA-TDB, based on the in-depth reviews and surveys on the various literature data, fulfilling the requirements of a proper geochemical modelling of the chemical 
behavior of radionuclides in natural environments. Moreover, various institutes such as JAEA [11], PSI/Nagra [12], and Andra [13] have also been developing customized chemical thermodynamic databases on the basis of OECD/NEA-TDB as a reference standard database. In particular, the thermodynamic database established by JAEA (JAEA-TDB) is being continuously updated and amended to provide further reliable and up to date chemical thermodynamic data. Moreover, OECD/NEA-TDB has been recently updated and revised for several major radionuclides such as $\mathrm{U}, \mathrm{Np}, \mathrm{Pu}, \mathrm{Am}$, and $\mathrm{Tc}$, and is expected to have a remarkable influence on various customized chemical thermodynamic databases.

According to the updated thermodynamic database, solubility and species distribution of aqueous radionuclides as primary parameters for the safety assessment model can be influenced based upon the chemical thermodynamic equilibrium, affecting source term of nuclear waste, migration/retardation behavior of relevant radionuclides, and eventually exposure doses from various radionuclides disposed in the waste repository. However, since the impact of those updated chemical thermodynamic databases on the primary parameters, i.e., solubility and species distribution, as well as exposure dose under natural environmental conditions can only be quantitatively evaluated by considering practical and conditional natural groundwater systems. Relevant thermodynamic calculations that take the information of those systems into account is essentially needed in this respect.

The RESRAD-OFFSITE [14] is a computational code for the safety assessment model developed by Argonne National Laboratory (ANL) on the basis of various hydrogeochemical parameters and radionuclide transport pathways such as direct external exposure, inhalation, ingestion, etc. The latest version of RESRAD-OFFSITE enables improved assessment of radionuclide migration in accordance with the radionuclide solubility as an input parameter. Therefore, the combination of RESRAD-OFFSITE code, solubility data, and species distribution derived from the relevant thermodynamic calculation is required to assess the impact of the updated chemical thermodynamic database on the exposure dose result and safety assessment model.

In the safety assessment modeling, the application of thermodynamic estimation is necessary for the calculation of radionuclides' solubility and relevant chemical species distribution to achieve more reliable prediction of the migration behavior of radionuclides. With respect to the computational thermodynamic estimation, two different approaches, the law of mass action (LMA) and the Gibbs energy minimization (GEM), were considered. The LMA approach is based on the equilibrium constant and mass balance function, while the GEM approach uses the Gibbs free energy function to derive the solution. The PHREEQC is an LMA-based computational code and can be used for the thermodynamic calculation of the hydrochemical behavior of radionuclides under a given aqueous system [15].

The objective of the present work is to investigate the influences of chemical thermodynamic data that have been recently updated by OECD/NEA on the default safety assessment model for the RESRAD-OFFSITE code with respect to the radioactive waste repository in terms of solubility, species distribution, and exposure dose from various radionuclides. The aqueous solubility of various radionuclides in natural groundwater systems was quantitatively predicted by using PHREEQC code, two different sets from the chemical thermodynamic database, and relevant safety assessment results, i.e., exposure dose values were derived consequently. According to the comparison between two different exposure dose results, information with respect to the major input parameters can be provided to achieve more reliable and precise safety assessment model calculations.

\section{Safety Assessment Model}

\subsection{Exposure Dose Calculation}

The exposure doses from various radionuclides were predicted by assuming low and intermediate level waste repository conditions and using the latest version (4.0) of RESRAD-OFFSITE computational code [14]. In the RESRAD-OFFSITE code version 4.0, the application of solubility data has been made possible so that a more accurate and reliable safety assessment can be achieved. With respect to the radionuclide migration mechanism, 
the one-dimensional advective-dispersive transport was employed to simulate the spread of contamination. The radionuclide transport was initiated with water infiltrating into the contaminated zone via rainfall by contact with radionuclides located in the contaminated medium. After that, the radionuclides were assumed to be vertically moving to the unsaturated and saturated zone located below the contaminated zone and transported horizontally within the saturated zone where groundwater presents. Finally, the contaminated groundwater induces successive contamination of the surrounding environment and human radiation exposure as well. Further detailed information with respect to the transport mechanism employed in the RESRAD-OFFSITE code is described elsewhere [16]. In the present work, all possible exposure pathways provided in the RESRAD-OFFSITE code such as direct exposure, inhalation, and ingestion were considered to evaluate the exposure dose. Moreover, all the input parameters describing the physicochemical properties of the repository site such as volume of contaminated zone, relevant geologic data of saturated and unsaturated zone, distribution coefficients of various radionuclides, etc. were set to the default values initially defined in the RESRAD-OFFISTE code [14] except for the radionuclide inventory and solubility data, which will be discussed in the following sections in detail.

\subsection{Radionuclide Inventory}

Table 1 shows the radionuclide inventory data employed in the present work taken from the literature [17] as the source term of waste repository. According to the literature [17], in total 13 radionuclides (H-3, C-14, Fe-55, Co-58, Co-60, Ni-59, Ni-63, Sr-90, $\mathrm{Nb}-94, \mathrm{Tc}-99$, I-129, Cs-137, and Ce-144) together with gross-alpha radionuclides were known to be major constituents in low and intermediate level waste. In the present work, the inventory of gross-alpha radionuclides was assumed to be equally distributed with $\mathrm{U}-238, \mathrm{Pu}-239, \mathrm{Am}-241$, and $\mathrm{Cm}-244$, as representatives of gross-alpha radionuclides for the exposure dose calculation. The authors note that the H-3, C-14, and I-129, widely known as major radionuclides in the early post-closure phase of low and intermediate level waste repository, were not considered in the present work, because those radionuclides are assumed to be soluble species and thus the updated chemical thermodynamic data do not provide meaningful influences on the solubility behavior of those radionuclides.

Table 1. Radionuclide inventories employed in the present work taken from the literature [17].

\begin{tabular}{ccc}
\hline Radionuclide & Inventory $\mathbf{( B q )}$ & Half-Life (Year) \\
\hline Fe-55 & $4.67 \times 10^{15}$ & 2.73 \\
Co-58 & $6.55 \times 10^{14}$ & $8.1 \times 10^{-3}$ \\
Co-60 & $1.03 \times 10^{15}$ & 5.27 \\
Ni-59 & $3.78 \times 10^{13}$ & $7.60 \times 10^{4}$ \\
Ni-63 & $2.71 \times 10^{15}$ & $1.00 \times 10^{2}$ \\
Sr-90 & $3.20 \times 10^{12}$ & $2.89 \times 10^{1}$ \\
Nb-94 & $9.72 \times 10^{10}$ & $2.03 \times 10^{4}$ \\
Tc-99 & $7.85 \times 10^{11}$ & $2.11 \times 10^{5}$ \\
Ce-144 & $6.81 \times 10^{11}$ & $7.81 \times 10^{-1}$ \\
Gross-alpha * & $6.22 \times 10^{11}$ & - \\
\hline${ }^{*}$. &
\end{tabular}

${ }^{*} \mathrm{U}-238, \mathrm{Pu}-239, \mathrm{Am}-241$, and $\mathrm{Cm}-244$ were considered as representatives of gross-alpha radionuclides.

\subsection{Chemical Thermodynamic Database}

For the solubility evaluation, fundamental chemical thermodynamic data such as formation constants and solubility product constants were collected from the literature [11,18]. The latest version of the JAEA thermodynamic database (JAEA-TDB) [11] was selected as the reference data in the present work. Moreover, the formation constants and solubility product constants of Tc, $\mathrm{Am}, \mathrm{U}$, and $\mathrm{Pu}$ that have been recently updated from the OECD/NEA Chemical Thermodynamics Vol. 14 [18] were additionally considered for the comparative study between the thermodynamic databases. Therefore, in the present work, 
two different sets of the chemical thermodynamic database, i.e., JAEA-TDB as reference data and amended JAEA-TDB reflecting the updates of the OECD/NEA Chemical Thermodynamics Vol. 14 (which will be referred to as updated TDB in the following sections) were employed to assess the influence of those updated data on the solubility evaluation and exposure dose calculation process. The chemical thermodynamic data of selected radionuclides, e.g., Tc, Am, $\mathrm{U}$, and $\mathrm{Pu}$ are represented in Table A1 in Appendix A. The authors note that the thermodynamic database established by the Lawrence Livermore National Laboratory [19] was alternatively adopted for the case of $\mathrm{Ce}$, of which data is not available in the JAEA-TDB.

For the thermodynamic calculation, the specific ion interaction theory (SIT) $[10,20]$ was used as an ionic strength correction model, because the validity range of the other ionic strength correction models, e.g., Davies model, Debye-Hückel model, etc., are relatively narrower than that of SIT [21]. According to the SIT formulism, the activity coefficients of (charged) aqueous species $\left(\gamma_{i}\right)$ are calculated as described in Equations (1) and (2):

$$
\begin{gathered}
\log \gamma_{i}=-z_{i}^{2} D+\Sigma \varepsilon_{i j} m_{j} \\
D=\frac{0.509 \sqrt{I_{m}}}{1+1.5 \sqrt{I_{m}}}
\end{gathered}
$$

where $z_{i}$ indicates the charge of the given ionic species, $D$ represents the Debye-Hückel term at $\mathrm{T}=25^{\circ} \mathrm{C}, \varepsilon_{i j}$ means the specific ion-interaction coefficient for a pair of oppositely charged ions, $m_{\mathrm{j}}$ corresponds to the molal concentration of the ion $j$, and $I_{m}$ is the molal ionic strength. Specific ion interaction coefficients used in the thermodynamic calculations performed in the present work were taken from the literature [11,18].

\subsection{Groundwater Composition and Solubility Estimation}

Because the solubility is one of the primary parameters in the RESRAD-OFFSITE code that influences the source term and exposure dose result, the solubility values of radionuclides of interest were predicted with PHREEQC computational code [15] considering the natural groundwater system. Total soluble concentration of the target radionuclide was derived according to the saturation indices of the relevant solid phases. Among the various solid phases present in the system, the one revealing the highest saturation index was selected to be the solubility limiting phase.

For the solubility evaluation, natural groundwater data of the Gyeongju low- and intermediate-level waste repository were taken from the literature [16] because there were no available default parameters regarding the groundwater composition in the RESRADOFFSITE code. The authors note that minor chemical constituents less than $1 \mathrm{ppm}$ in their concentrations were excluded in the solubility calculation due to their negligible influences on the thermodynamic calculation. In addition, the temperature of target groundwater was set to $\mathrm{T}=25^{\circ} \mathrm{C}$ for the simple estimation. Detailed information regarding relevant geochemical parameters of natural groundwater utilized for the solubility estimation is presented in Table 2. 
Table 2. Geochemical parameters of the natural groundwater system employed in this work.

\begin{tabular}{|c|c|}
\hline Parameter & Value \\
\hline $\mathrm{pH}$ & $7.4 \pm 0.9$ \\
\hline$E_{h}$ & $155 \pm 31 \mathrm{mV}$ \\
\hline Ionic strength & $8.3 \times 10^{-2} \mathrm{~mol} / \mathrm{kg}_{\mathrm{w}}$ \\
\hline Constituent & Concentration $\left(\mathrm{mol} / \mathrm{kg}_{\mathrm{w}}\right)$ \\
\hline $\mathrm{Na}$ & $3.8 \times 10^{-2}$ \\
\hline $\mathrm{K}$ & $1.0 \times 10^{-3}$ \\
\hline $\mathrm{Ca}$ & $7.9 \times 10^{-3}$ \\
\hline $\mathrm{Mg}$ & $5.8 \times 10^{-3}$ \\
\hline $\mathrm{SiO}_{2}$ & $6.0 \times 10^{-4}$ \\
\hline $\mathrm{Cl}^{-}$ & $5.7 \times 10^{-2}$ \\
\hline $\mathrm{SO}_{4}^{2-}$ & $3.5 \times 10^{-3}$ \\
\hline Alkalinity as $\mathrm{HCO}_{3}^{-}$ & $1.5 \times 10^{-3}$ \\
\hline $\mathrm{Br}^{-}$ & $1.7 \times 10^{-4}$ \\
\hline $\mathrm{Fe}$ & $8.5 \times 10^{-5}$ \\
\hline $\mathrm{Mn}$ & $4.3 \times 10^{-5}$ \\
\hline $\mathrm{Sr}$ & $1.4 \times 10^{-5}$ \\
\hline
\end{tabular}

\section{Results}

The solubility values of various radionuclides in natural groundwater system estimated by using PHREEQC to derive the source term of exposure dose are represented in Table 3. In most cases, the solubility data calculated with two different chemical thermodynamic databases, i.e., JAEA-TDB and updated TDB, were largely consistent with each other, except for the case of, $\mathrm{U}$ which showed a slightly increased aqueous solubility. According to thermodynamic calculation, the predominant presence of oxides (e.g., $\mathrm{Ce}, \mathrm{Fe}, \mathrm{Nb}, \mathrm{Pu}$, and Tc), carbonates (e.g., Co and Ni), and ternary carbonate hydroxide solid phases (e.g., $\mathrm{Am}$ and $\mathrm{Cm}$ ) were identified as the solubility limiting phase under the given groundwater system. In all cases, no changes in the solubility limiting phase were observed for both thermodynamic database cases, which also match well with the behavior of the solubility data of each radionuclide in terms of the selection of the thermodynamic database.

Table 3. Solubility data of various radionuclides in a natural groundwater system estimated using JAEA-TDB and updated TDB.

\begin{tabular}{cccl}
\hline \multirow{2}{*}{ Radionuclide } & \multicolumn{2}{c}{ Solubility at $\mathbf{p H} \mathbf{7 . 4}\left(\mathbf{m o l} / \mathbf{k g}_{\mathbf{w}}\right)$} & \multirow{2}{*}{ Solubility Limiting Phase } \\
\cline { 2 - 3 } & JAEA-TDB & Updated TDB & \\
\hline $\mathrm{Am}$ & $1.54 \times 10^{-7}$ & $1.57 \times 10^{-7}$ & \\
$\mathrm{Ce}$ & $1.46 \times 10^{-10}$ & $1.42 \times 10^{-10}$ & $\mathrm{AmCO}_{3} \mathrm{OH} \cdot 0.5 \mathrm{H}_{2} \mathrm{O}(\mathrm{cr})$ \\
$\mathrm{Cm}$ & $1.54 \times 10^{-7}$ & $1.54 \times 10^{-7}$ & \\
$\mathrm{Cm}(\mathrm{cr})$ \\
$\mathrm{Co}$ & $9.51 \times 10^{-5}$ & $9.45 \times 10^{-5}$ & $\mathrm{CoCO}_{3}\left(\mathrm{cr} \cdot 0.5 \mathrm{H}_{2} \mathrm{O}(\mathrm{cr})\right.$ \\
$\mathrm{Fe}$ & $3.61 \times 10^{-12}$ & $3.57 \times 10^{-12}$ & $\mathrm{Fe}_{2} \mathrm{O}_{3}(\mathrm{~s})$ \\
$\mathrm{Nb}$ & $1.42 \times 10^{-7}$ & $1.42 \times 10^{-7}$ & $\mathrm{Nb}_{2} \mathrm{O}_{5}(\mathrm{~s})$ \\
$\mathrm{Ni}$ & $9.54 \times 10^{-5}$ & $9.43 \times 10^{-5}$ & $\mathrm{NiCO}_{3}(\mathrm{cr})$ \\
$\mathrm{Pu}$ & $7.40 \times 10^{-17}$ & $7.20 \times 10^{-17}$ & $\mathrm{PuO}_{2}(\mathrm{cr})$ \\
$\mathrm{Sr}$ & $7.32 \times 10^{-4}$ & $7.29 \times 10^{-4}$ & $\mathrm{SrSO}_{4}(\mathrm{~s})$ \\
$\mathrm{U}$ & $8.40 \times 10^{-5}$ & $8.37 \times 10^{-5}$ & $\mathrm{TcO}_{2}(\mathrm{cr})$ \\
\hline
\end{tabular}

By using the solubility data of various radionuclides as the source term, exposure dose expected from the waste repository was predicted with the RESRAD-OFFSITE code as represented in Figure 1. The authors note that the exposure dose result obtained in this work does not represent that of Gyeongju repository but of the default model of RESRADOFFSITE code, since all the input parameters were set to be the default values of RESRADOFFSITE code, except for radionuclide inventory and aqueous solubility. The obtained 
result represented similar or negligibly changed exposure doses between the JAEA-TDB and the updated TDB due to the remarkable similarity between the solubility data. The relationship between the obtained exposure dose result and chemical thermodynamic data in terms of solubility and chemical species distribution will be further discussed in detail in the following section.
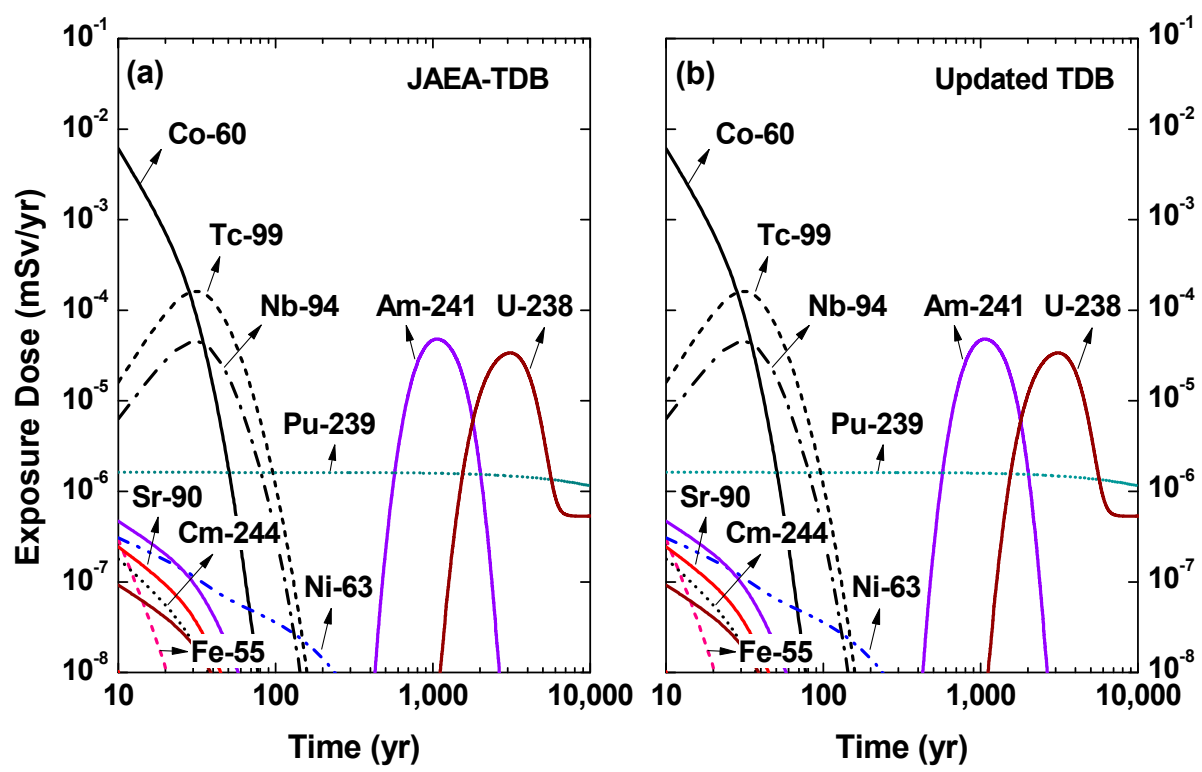

Figure 1. Exposure dose from various radionuclides derived by using solubility data estimated from (a) JAEA-TDB and (b) updated TDB as the source term.

\section{Discussion}

The notable similarities between exposure dose results obtained with two different thermodynamic databases were mainly due to the relatively minor influences of newly added and/or updated chemical species in the solubility data. In this regard, the relative abundance of aqueous chemical species of various radionuclides, which can influence the solubility data and other input parameters, was quantitatively calculated from the relevant equilibrium reactions. As shown in Figure $2 \mathrm{a}$, species distributions of Am indicated the predominant presence of $\mathrm{AmSiO}(\mathrm{OH})_{3}{ }^{2+}$ together with $\mathrm{AmCO}_{3}{ }^{+}$and $\mathrm{Am}^{3+}$, and revealed almost identical compositions with respect to two different sets of thermodynamic databases. The almost unchanged species distribution of Am under the given groundwater system results from a relatively weak affinity between $\mathrm{Am}$ and $\mathrm{Cl}^{-} / \mathrm{SO}_{4}{ }^{2-}$ ions under the given groundwater system as well as a trivial change in the updated formation constants of $\mathrm{AmSiO}(\mathrm{OH})_{3}{ }^{2+}$ species from $\log \mathrm{K}^{0}=-(1.68 \pm 0.18)$ [11] to $\log \mathrm{K}^{0}=-(1.67 \pm 0.20)$ [18]. The behaviors of solubility data and aqueous species distributions of most of the other radionuclides presents nearly unchanged results for both JAEA-TDB and updated TDB, which were comparable to those of the Am case. For the Tc case, even though various chemical species such as $\mathrm{TcCl}_{5}{ }^{-}, \mathrm{TcCl}_{6}{ }^{2-}$, and $\mathrm{Tc}_{2} \mathrm{OCl}_{10}{ }^{4-}$ were newly included in the updated TDB, no significant change in solubility and species distribution was identified for similar reasons to the case of $\mathrm{Am}$. For the case of $\mathrm{Pu}$, the solubility limiting phase was determined to be $\mathrm{PuO}_{2}(\mathrm{cr})$, with exceptional stability of $\log \mathrm{K}^{0}{ }_{\mathrm{sp}}=-(64.0 \pm 0.5)[11,18]$ in aqueous systems compared with the other Pu solid phases, for both calculations with two different TDBs. According to the thermodynamic calculation, a relatively minor change in Pu solubility was identified because (i) there was no update for the solubility product constant of $\mathrm{PuO}_{2}(\mathrm{cr})$ and the other tetravalent aqueous Pu species; (ii) the oxidation state of $\mathrm{Pu}$ under the given groundwater system was expected to be tetravalency; and (iii) the stability of the other oxidation states, i.e., $\mathrm{Pu}(\mathrm{III}), \mathrm{Pu}(\mathrm{IV})$, and $\mathrm{Pu}(\mathrm{V})$, was remarkably low so that the abundance of newly added or updated Pu species in the species distribution was identified as being very minor. 


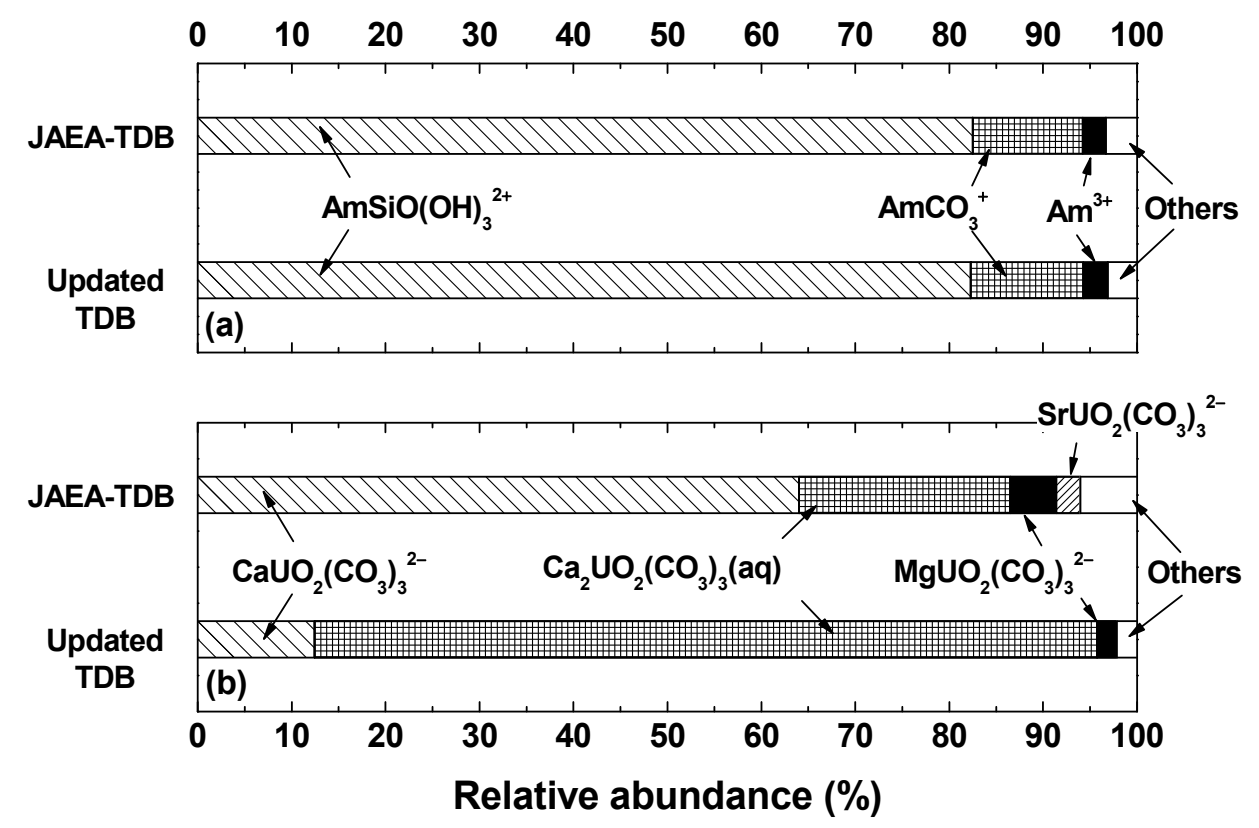

Figure 2. Relative distribution of aqueous (a) Am and (b) U species predicted by using JAEA-TDB and updated TDB, respectively. Chemical species less than $2 \%$ in their abundances are merged as "others".

On the contrary, in the case of $U$ in particular, remarkable discrepancies in solubility data and aqueous species distribution were identified between thermodynamic calculation results obtained with JAEA-TDB and updated TDB. For all cases, the chemistry of $U$ in natural groundwater systems was mostly governed by ternary $\mathrm{Mg} / \mathrm{Ca}-\mathrm{UO}_{2}-\mathrm{CO}_{3}$ complexes because of exceptionally strong chemical affinity among earth alkaline metal ions, $\mathrm{UO}_{2}{ }^{2+}$ free ion, and $\mathrm{CO}_{3}{ }^{2-}$ ion [3,22-25]. Moreover, thermodynamic calculations using JAEA-TDB revealed that negatively charged $\mathrm{CaUO}_{2}\left(\mathrm{CO}_{3}\right)_{3}{ }^{2-}$ species presents predominantly under the given system, whereas a remarkable formation of uncharged $\mathrm{Ca}_{2} \mathrm{UO}_{2}\left(\mathrm{CO}_{3}\right)_{3}(\mathrm{aq})$ species was expected based on the updated TDB (see Figure 2b), even in the same groundwater condition.

A slight increase in $\mathrm{U}$ solubility for the calculation with the updated TDB (see Table 3) is mainly due to the further formation of $\mathrm{Ca}_{2} \mathrm{UO}_{2}\left(\mathrm{CO}_{3}\right)_{3}(\mathrm{aq})$, which can provide additional stability for the dissolved $\mathrm{U}$ species according to the remarkably increased formation constant of $\mathrm{Ca}_{2} \mathrm{UO}_{2}\left(\mathrm{CO}_{3}\right)_{3}(\mathrm{aq})$ selected in the updated TDB compared with that in the JAEA-TDB. A significant change in the updated formation constant of $\mathrm{Ca}_{2} \mathrm{UO}_{2}\left(\mathrm{CO}_{3}\right)_{3}(\mathrm{aq})$ species from $\log \mathrm{K}^{0}=29.22 \pm 0.26$ [11] to $\log \mathrm{K}^{0}=30.80 \pm 0.40$ [18], indicating the increase of $\log \mathrm{K}^{0}$ by almost an order of magnitude, allowed for the domination of the aqueous groundwater system by $\mathrm{Ca}_{2} \mathrm{UO}_{2}\left(\mathrm{CO}_{3}\right)_{3}(\mathrm{aq})$ species, according to the updated TDB. On the other hand, the relative abundance of $\mathrm{Sr}$ ion bound $\mathrm{U}$ species became negligible owing to the remarkable decrease in the formation constant, from $\log \mathrm{K}^{0}=26.86 \pm 0.50$ [11] to $\log \mathrm{K}^{0}=25.90 \pm 0.20$ [18], of $\mathrm{SrUO}_{2}\left(\mathrm{CO}_{3}\right)_{3}{ }^{2-}$ species. Furthermore, electrically neutral $\mathrm{U}$ species other than $\mathrm{Ca}_{2} \mathrm{UO}_{2}\left(\mathrm{CO}_{3}\right)_{3}$ (aq) such as $\mathrm{Mg}_{2} \mathrm{UO}_{2}\left(\mathrm{CO}_{3}\right)_{3}(\mathrm{aq})$ and $\mathrm{Sr}_{2} \mathrm{UO}_{2}\left(\mathrm{CO}_{3}\right)_{3}(\mathrm{aq})$, which were newly included in the updated TDB, did not show substantial abundance in $\mathrm{U}$ species distribution on account of either an exceptionally weak formation constant (for $\mathrm{Mg}$ case) or a very low aqueous concentration of the metal ion in the groundwater system (for Sr case).

Even though the exposure dose results for both thermodynamic databases are similar to each other, the updated TDB still provides an insight into the precise exposure dose estimation in terms of the distribution coefficient $(\mathrm{Kd})$. In particular, in case of $\mathrm{U}$, the predominant aqueous species was considerably changed from a negatively charged species, $\mathrm{CaUO}_{2}\left(\mathrm{CO}_{3}\right)_{3}{ }^{2-}$, to an uncharged species, $\mathrm{Ca}_{2} \mathrm{UO}_{2}\left(\mathrm{CO}_{3}\right)_{3}(\mathrm{aq})$, according to the selection of the thermodynamic database. Therefore, the distribution coefficient of $U$ against the 
mineral surface, e.g., aluminosilicate minerals, which are negatively charged in natural groundwater systems [26], can also be dramatically changed because the electrostatic repulsion between the $\mathrm{U}$ species and the mineral surface will be decreased significantly. Figure 3 represents the exposure dose results of U-238 calculated with updated TDB at various distribution coefficients, unambiguously indicating that the distribution coefficient acts as a key parameter that can promote/increase or delay/decrease the peak time and peak value of the exposure dose, respectively.

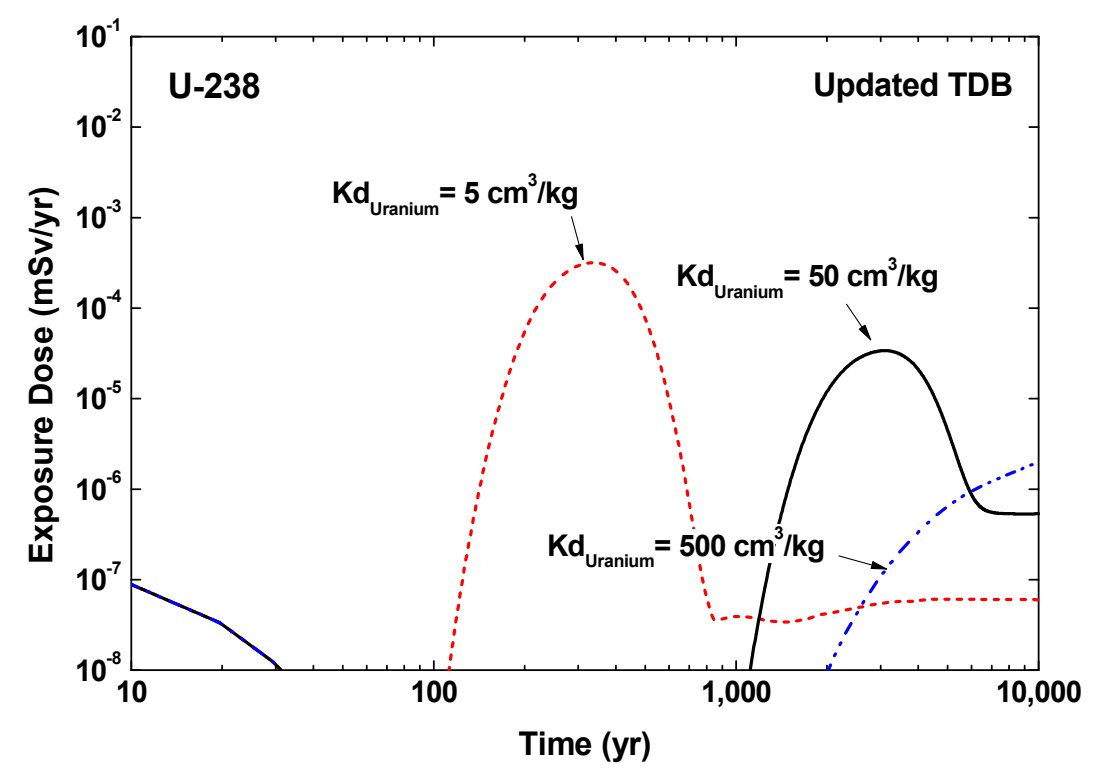

Figure 3. Exposure dose from U-238 calculated with updated TDB at various distribution coefficient $(\mathrm{Kd})$ values.

In comparison to the default Kd value of RESRAD-OFFSITE code $\left(50 \mathrm{~cm}^{3} / \mathrm{kg}\right.$ for U-238) against geologic barriers in repository sites, the enhanced $K d$ value of $500 \mathrm{~cm}^{3} / \mathrm{kg}$, set to be 10 times higher than the default value, presents a significant delay in the release rate of U-238 into the biosphere due to the remarkably enhanced retardation capacity. On the other hand, the result obtained with a relatively decreased $K d$ value of $5 \mathrm{~cm}^{3} / \mathrm{kg}$, 10 times lower than the default value, was contrary to that predicted with the enhanced $\mathrm{Kd}$ value, revealing a remarkably increased and accelerated exposure dose value and peak time. From this perspective, it provides a hint towards further precise evaluation of the exposure dose by means of achieving a reliable estimation of the distribution coefficient. The current safety assessment model based on the single-valued distribution coefficient for each particular zone in the repository site might not precisely reflect the fundamental geochemical parameters, e.g., $\mathrm{pH}$, ionic strength, aqueous ion concentrations, which vary over the site. Therefore, further systematic approaches based on the solid-water interfacial reaction such as surface complexation model $[27,28]$, as well as a precise chemical speciation calculation with an up to date chemical thermodynamic database is expected to provide a more accurate and site-specific distribution coefficient, enhancing the reliability of exposure dose result and safety assessment models.

\section{Conclusions}

In the present work, the impact of updated chemical thermodynamic data on the safety assessment model was evaluated by using RESRAD-OFFSITE and PHREEQC computational codes. According to the results obtained with thermodynamic calculations, the solubility data derived by using two different sets of chemical thermodynamic databases were very similar to each other, except for the case of U providing a slightly increased solubility value with the updated TDB. Still, because of the remarkable similarity in solubility values of various radionuclides obtained with both JAEA-TDB and updated TDB, almost 
identical exposure dose results were evaluated, indicating that the influence of the updated chemical thermodynamic data was relatively minor from the viewpoint of the solubility. However, dramatic changes in exposure dose were observed with varying distribution coefficients. For the case of U-238, a relatively increased distribution coefficient revealed a remarkably delayed release rate owing to the enhanced retention capacity of geologic barriers, while significant acceleration in peak time of the exposure dose for U-238 was identified with a decreased distribution coefficient condition.

The authors note that the exposure dose result obtained in this work does not represent that of Gyeongju repository but of the default model of RESRAD-OFFSITE code because all the input parameters employed in the present work were the default values of RESRADOFFSITE code, except for the radionuclide inventory and aqueous solubility data.

To the best of the authors' knowledge, this work is the first case evaluating the influence of the updated chemical thermodynamic database on the safety assessment model based on the RESRAD-OFFSITE code. This study confirmed that the impact of the updated chemical thermodynamic data was relatively minor in terms of solubility and that the selection of chemical thermodynamic database can produce significant change in species distribution in natural groundwater systems. The change in predominant species in aqueous solution is expected to provide a substantial influence on the solid-water interfacial reaction, as well as relevant distribution coefficients. In this regard, according to the close relationship between the predominant chemical species and distribution coefficient, the exposure dose results with various distribution coefficients obtained in the present work indicated that further systematic approaches by means of surface complexation models, which can predict the distribution coefficient as a function of groundwater composition, coupled with chemical speciation calculations based on up to date chemical thermodynamic data is required to produce more reliable site-specific distribution coefficients and to enhance the accuracy of safety assessment models.

Author Contributions: Conceptualization, J.-Y.L.; methodology, J.-Y.L. and S.A.; software, S.J.P.; validation, J.-Y.L. and S.A.; formal analysis, J.-Y.L.; investigation, J.-Y.L. and S.J.P.; resources, J.-Y.L.; data curation, J.-Y.L. and S.J.P.; writing—original draft preparation, J.-Y.L.; writing—review and editing, J.-Y.L. and S.A.; visualization, J.-Y.L.; supervision, J.-Y.L. and S.A.; project administration, J.-Y.L.; funding acquisition, J.-Y.L. All authors have read and agreed to the published version of the manuscript.

Funding: This work was supported by a two year research grant from Pusan National University.

Institutional Review Board Statement: Not applicable.

Informed Consent Statement: Not applicable.

Data Availability Statement: The data used in this study are available within this article.

Conflicts of Interest: The authors declare no conflict of interest. 


\section{Appendix A}

Table A1. Chemical thermodynamic data of various radionuclides taken from the JAEA-TDB [11] and OECD/NEA Chemical Thermodynamics Vol. 14 [18].

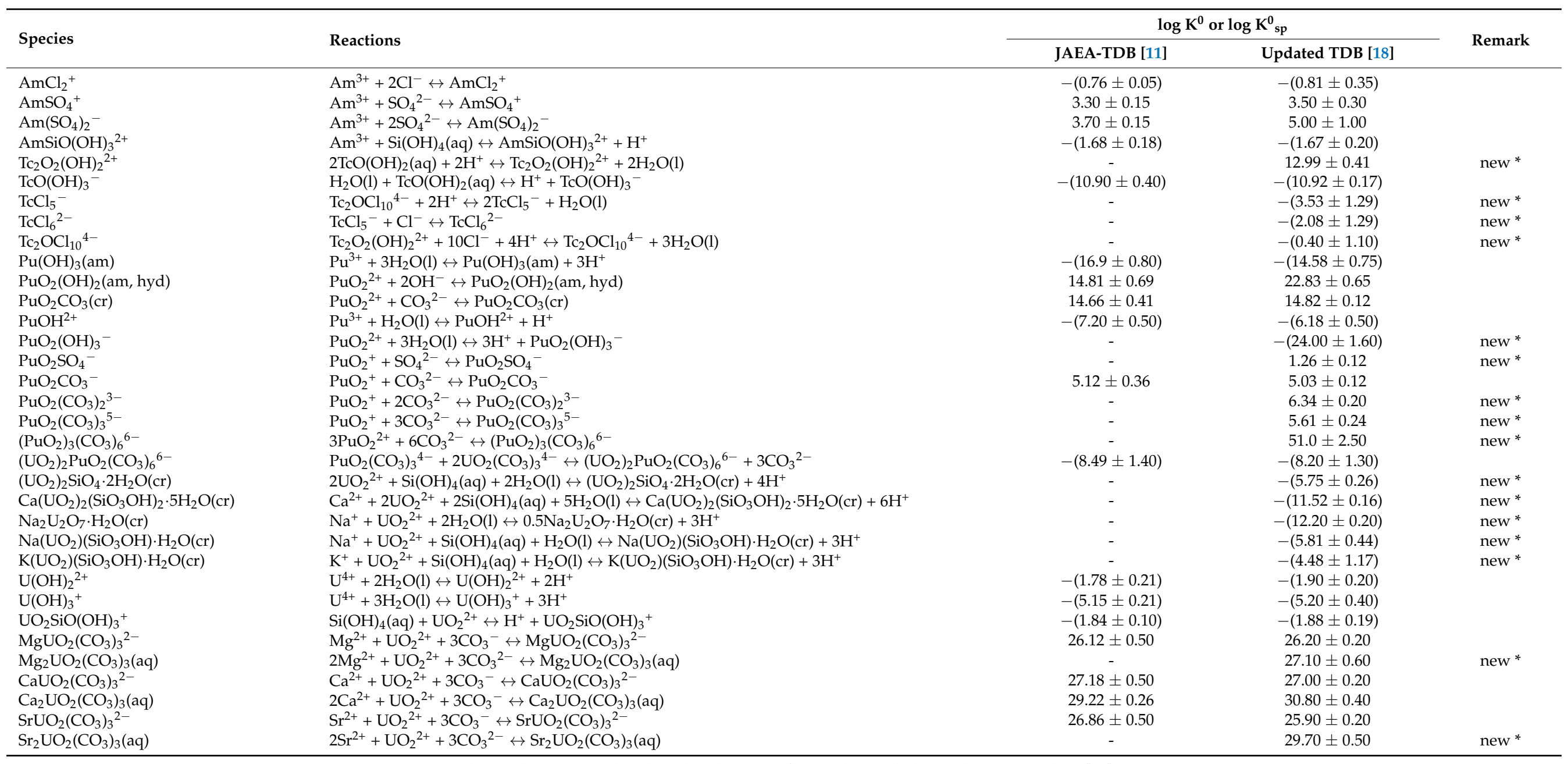

${ }^{*}$ Chemical species newly selected in the OECD/NEA Chemical Thermodynamics Vol. 14 [18]. 


\section{References}

1. Kim, J.I.; Grambow, B. Geochemical Assessment of Actinide Isolation in a German Salt Repository Environment. Eng. Geol. 1999, 52, 221-230. [CrossRef]

2. Lee, J.-Y.; Yun, J.-I. Temperature-dependent Hydrolysis Reactions of UVI) Studied by TRLFS. J. Nucl. Fuel Cycle Waste Technol. 2013, 1, 65-73. [CrossRef]

3. Dong, W.; Brooks, S.C. Determination of the Formation Constants of Ternary Complexes of Uranyl and Carbonate with Alkaline Earth Metals $\left(\mathrm{Mg}^{2+}, \mathrm{Ca}^{2+}, \mathrm{Sr}^{2+}\right.$, and $\left.\mathrm{Ba}^{2+}\right)$ Using Anion Exchange Method. Environ. Sci. Technol. 2006, 40, 4689-4695. [CrossRef] [PubMed]

4. Endrizzi, F.; Gaona, X.; Marques Fernandes, M.; Baeyens, B.; Altmaier, M. Solubility and hydrolysis of U(VI) in $0.5 \mathrm{~mol} / \mathrm{kg} \mathrm{NaCl}$ solutions at $\mathrm{T}=22$ and $80^{\circ} \mathrm{C}$. J. Chem. Thermodyn. 2018, 120, 45-53. [CrossRef]

5. Lee, J.-Y.; Amayri, S.; Montoya, V.; Fellhauer, D.; Gaona, X.; Altmaier, M. Solubility and stability of liebigite, $\mathrm{Ca}_{2} \mathrm{UO}_{2}\left(\mathrm{CO}_{3}\right)_{3} \cdot 10 \mathrm{H}_{2} \mathrm{O}(\mathrm{cr})$, in dilute to concentrated $\mathrm{NaCl}$ and $\mathrm{NaClO}_{4}$ solutions at $\mathrm{T}=22-80{ }^{\circ} \mathrm{C}$. Appl. Geochem. 2019, 111, 104374. [CrossRef]

6. Altmaier, M.; Yalçıntaş, E.; Gaona, X.; Neck, V.; Müller, R.; Schlieker, M.; Fanghänel, T. Solubility of U(VI) in chloride solutions. I. The stable oxides/hydroxides in $\mathrm{NaCl}$ systems, solubility products, hydrolysis constants and SIT coefficients. J. Chem. Thermodyn. 2017, 114, 2-13. [CrossRef]

7. Jo, Y.; Lee, J.-Y.; Yun, J.-I. Adsorption of uranyl tricarbonate and calcium uranyl carbonate onto $\gamma$-alumina. Appl. Geochem. 2018, 94, 28-34. [CrossRef]

8. Zou, Y.; Chen, T.; Yuan, G.; Zhang, K. Sorption of iodine on Beishan granite: Effect of speciation and humic acid. J. Radioanal. Nucl. Chem. 2018, 317, 723-730. [CrossRef]

9. Grenthe, I.; Fuger, J.; Konings, R.J.M.; Lemire, R.J.; Muller, A.B.; Cregu, C.N.-T.; Wanner, H. Chemical Thermodynamics of Uranium; Elsevier: Amsterdam, The Netherlands; OECD-NEA: Amsterdam, The Netherlands, 1992; Volume 1.

10. Guillaumont, R.; Fanghänel, T.; Neck, V.; Fuger, J.; Palmer, D.A.; Grenthe, I.; Rand, M.H. Update on the Chemical Thermodynamics of Uranium, Neptunium, Plutonium, Americium and Technetium; Elsevier: Amsterdam, The Netherlands; OECD-NEA: Amsterdam, The Netherlands, 2003; Volume 5.

11. Kitamura, A. Update of JAEA-TDB: Update of Thermodynamic Data for Zirconium and Those for Isosaccahrinate, Tentative Selection of Thermodynamic Data for Ternary M2+-UO22+-CO32- System and Integration with JAEA's Thermodynamic Database for Geochemical Calculations; JAEA: Tokai, Japan, 2019. [CrossRef]

12. Thoenen, T.; Hummel, W.; Berner, U.; Curti, E. The PSI/Nagra Chemical Thermodynamic Database 12/07; Paul Scherrer Institut: Villigen, Switzerland, 2014.

13. Giffaut, E.; Grivé, M.; Blanc, P.; Vieillard, P.; Colàs, E.; Gailhanou, H.; Gaboreau, S.; Marty, N.; Madé, B.; Duro, L. Andra thermodynamic database for performance assessment: ThermoChimie. Appl. Geochem. 2014, 49, 225-236. [CrossRef]

14. Yu, C.; Gnanapragasam, E.; Cheng, J.-J.; LePoire, D.; Kamboj, S.; Wang, C. User's Manual for RESRAD-OFFSITE Code Version 4; Argonne National Laboratory Lemont: Lemont, IL, USA, 2020.

15. Charlton, S.R.; Parkhurst, D.L. Modules based on the geochemical model PHREEQC for use in scripting and programming languages. Comput. Geosci. 2011, 37, 1653-1663. [CrossRef]

16. Park, S.J.; Shin, B.S.; Ahn, S.; Lee, J.-Y. Safety assessment of second-phase disposal facility in Gyeongju low- and intermediate-level radioactive waste (LILW) repository using RESRAD-OFFSITE code. J. Nucl. Sci. Technol. 2021. [CrossRef]

17. Han, S.-C. Interdependent Safety Assessment of Integrated Low-and Intermediate Radioactive Waste Disposal System in the Republic of Korea; KAIST: Daejeon, Korea, 2015.

18. Grenthe, I.; Gaona, X.; Plyasunov, A.V.; Rao, L.; Runde, W.H.; Grambow, B.; Konings, R.J.M.; Smith, A.L.; Moore, E.E. Second Update on the Chemical Thermodynamics of Uranium, Neptunium, Plutonium, Americium, and Technetium; OECD-NEA: Paris, France, 2020; Volume 14.

19. Johnson, J.; Anderson, F.; Parkhurst, D.L. Database Thermo.com.V8.R6.230; Lawrence Livermore National Laboratory: Livermore, CA, USA, 2000.

20. Ciavatta, L. The Specific Interaction Theory in Evaluating Ionic Equilibria. Ann. Chim. 1980, 70, 551-567.

21. Neck, V.; Kim, J.I. Solubility and Hydrolysis of Tetravalent Actinides; Forschungszentrum Karlsruhe: Karlsruhe, Germany, 1999.

22. Lee, J.-Y.; Yun, J.-I. Formation of ternary $\mathrm{CaUO}_{2}\left(\mathrm{CO}_{3}\right)_{3}{ }^{2-}$ and $\mathrm{Ca}_{2} \mathrm{UO}_{2}\left(\mathrm{CO}_{3}\right)_{3}(\mathrm{aq})$ complexes under neutral to weakly alkaline conditions. Dalton Trans. 2013, 42, 9862-9869. [CrossRef] [PubMed]

23. Endrizzi, F.; Leggett, C.J.; Rao, L. Scientific Basis for Efficient Extraction of Uranium from Seawater. I: Understanding the Chemical Speciation of Uranium under Seawater Conditions. Ind. Eng. Chem. Res. 2016, 55, 4249-4256. [CrossRef]

24. Lee, J.-Y.; Vespa, M.; Gaona, X.; Dardenne, K.; Rothe, J.; Rabung, T.; Altmaier, M.; Yun, J.-I. Formation, stability and structural characterization of ternary $\mathrm{MgUO}_{2}\left(\mathrm{CO}_{3}\right)_{3}{ }^{2-}$ and $\mathrm{Mg}_{2} \mathrm{UO}_{2}\left(\mathrm{CO}_{3}\right)_{3}$ (aq) complexes. Radiochim. Acta 2017, 105, 171-185. [CrossRef]

25. Bernhard, G.; Geipel, G.; Reich, T.; Brendler, V.; Amayri, S.; Nitsche, H. Uranyl(VI) Carbonate Complex Formation: Validation of the $\mathrm{Ca}_{2} \mathrm{UO}_{2}\left(\mathrm{CO}_{3}\right)_{3}$ (aq.) Species. Radiochim. Acta 2001, 89, 511-518. [CrossRef]

26. Geckeis, H.; Lützenkirchen, J.; Polly, R.; Rabung, T.; Schmidt, M. Mineral-Water Interface Reactions of Actinides. Chem. Rev. 2013, 113, 1016-1062. [CrossRef] [PubMed] 
27. Bradbury, M.H.; Baeyens, B. Sorption modelling on illite. Part II: Actinide sorption and linear free energy relationships. Geochim. Cosmochim. Acta 2009, 73, 1004-1013. [CrossRef]

28. Bradbury, M.H.; Baeyens, B. Sorption modelling on illite Part I: Titration measurements and the sorption of Ni, Co, Eu and Sn. Geochim. Cosmochim. Acta 2009, 73, 990-1003. [CrossRef] 